

\section{NOVOS DIREITOS}

| POR MARIA CECÍLIA OLIVEIRA GOMES

\section{A Lei Geral de Proteção de Dados Pessoais traz aspectos inéditos que afetam a gestão das empresas. Confira quais são e como cumpri-los.}

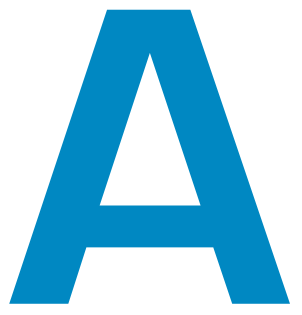

Lei Geral de Proteção de Dados Pessoais (LGPDP), sancionada no ano passado, entra em vigor em agosto de 2020. Até lá, as empresas vão ter de se reorganizar para atender aos direitos dos titulares de dados. Mas como fazê-lo?

No ordenamento jurídico brasileiro, já existiam mais de 40 leis, resoluções e normativas setoriais sobre o tema, mas elas nem sempre eram cumpridas. A LGPDP (Lei $\mathrm{n}^{\circ}$ 13.709/2018) engloba a proteção já conferida nas legislações anteriores, como a possibilidade de os cidadãos confirmarem, acessarem, corrigirem e excluírem seus dados, com a diferença que agora há a sinalização de que a fiscalização será mais rigorosa.

A LGPDP também atende a novos direitos, os quais foram gestados mais recentemente por conta do volume expressivo de tratamento de dados automatizados na era do big data e da dificuldade de proteger os seus titulares. A utilização de algoritmos para definir o perfil de um indivíduo corre o risco de utilizar critérios pouco claros que resultam em decisões discriminatórias e prejuízos aos titulares de dados.

\section{QUAIS SÃO OS NOVOS DIREITOS?}

Podemos identificar 13 direitos nos artigos 18 e 20 da LGPDP. Quem deve atender a eles são os chamados agentes de tratamento, nesse caso, controladores e operadores. Controlador é o responsável por determinar quais dados pessoais devem ser coletados. Por exemplo, quando uma farmácia pede o cadastro de pessoa física (CPF) ou outro dado do seu cliente para o seu programa de fidelidade, ela é controladora e responsável por essa relação. Já os operadores vão agir a pedido ou em nome dos controladores. Utilizando o mesmo exemplo, o software usado para emissão de nota fiscal é da empresa operadora, que, a pedido da farmácia, vai tratar os dados.

Para facilitar a compreensão e torná-la mais acessível, podemos classificar os direitos da seguinte forma:

- direitos tradicionais, já presentes em leis setoriais de proteção de dados no Brasil;

- direitos novos, incorporados na LGPDP por meio do Regulamento Geral sobre a Proteção de Dados (GDPR), ou expandidos.

Quanto aos direitos tradicionais, podemos identificá-los nos seguintes direitos:

- confirmação da existência de tratamento;

- acesso aos dados;

- correção de dados incompletos, inexatos ou desatualizados. Já os novos podemos encontrar nos seguintes direitos:

- anonimização, bloqueio ou eliminação de dados desnecessários, excessivos ou tratados em desconformidade;

- portabilidade dos dados; 


\section{Caso fique comprovado que determinada empresa não possui um padrão de segurança adequado para fazer uso dos dados pessoais coletados, pode ser impedida de continuar realizando o tratamento deles.}

- eliminação dos dados pessoais tratados com o consentimento do titular;

- informação das entidades públicas e privadas com as quais o controlador realizou uso compartilhado de dados;

- informação sobre a possibilidade de não fornecer consentimento e sobre as consequências da negativa;

- revogação do consentimento;

- direito de peticionar em relação aos seus dados contra o controlador perante a autoridade nacional;

- direito de oposição nas hipóteses de dispensa de consentimento;

- direito de revisões de decisões automatizadas;

- direito à explicação.

Atualmente, controladores e operadores estão preocupados em entender esses novos direitos e em como atender a eles. Destacamos quatro deles que estão sendo alvo de intensos debates hoje no Brasil, os direitos de:

- anonimização, bloqueio e eliminação;

- portabilidade;

- revisão de decisão automatizada;

- direito à explicação.

Em relação ao primeiro, de forma breve, vale explicar que, na anonimização, é possível descaracterizar dados para que não seja possível a reidentificação do titular deles. Dados anonimizados não são dados pessoais. Por isso, em caso de incidente de segurança, se a base de dados estiver anonimizada, o dano causado é menor. No caso do bloqueio, caso fique comprovado que determinada empresa não possui um padrão de segurança adequado para fazer uso dos dados pessoais coletados, é possível que seja impedida de continuar realizando o tratamento deles, até que seu padrão de segurança seja melhorado.

A eliminação é o pedido de exclusão dos dados pessoais pelo próprio titular dos dados. Caso um usuário encerre sua conta de e-mail, por exemplo, pode solicitar à empresa que fornece o serviço para apagar seus dados pessoais; esta só pode se recusar a fazê-lo se tiver uma justificativa legal. Dados relacionados ao IP, que ficam armazenados em cada uma das vezes em que o e-mail é acessado, devem obrigatoriamente ser guardados pela empresa de correio eletrônico pelo prazo de seis meses, em cumprimento ao Marco Civil da Internet.

Já a portabilidade está relacionada à possibilidade de o titular portar ou transmitir seus dados pessoais de um controlador para outro. Os dados devem ter caráter estruturado e interoperável, a fim de facilitar a transmissão. Muitas empresas estão preocupadas em como atender a esse direito. A verdade é que a LGPDP não traz critérios claros sobre o tema e, enquanto isso não é esclarecido pela Autoridade Nacional de Proteção de Dados (ANPD), é recomendável que as empresas comecem a fazer um inventário para estruturar e catalogar as bases de dados pessoais que retêm.

A revisão de decisão automatizada refere-se à possibilidade de a decisão tomada unicamente com base em tratamento automatizado ser revista quando impactar os interesses dos titulares, a fim de evitar decisões discriminatórias. Um exemplo clássico é o do credit score, quando um titular deseja obter crédito para comprar um produto, mas tem seu pedido negado, porque um algoritmo entendeu que ele não teria capacidade financeira para pagar o empréstimo. Esse direito já estava presente na Lei de Cadastro Positivo, especificamente para a finalidade de crédito, tendo sido agora na LGPDP expandido para outros tipos de finalidades de tratamento de dados, como a possibilidade de revisão do que o algoritmo entende que você iria gostar de ver na sua timeline do Facebook ou do Instagram (propagandas, fotos, vídeos etc.).

Por fim, o direito à explicação é a possibilidade de o titular dos dados requerer esclarecimentos sobre os critérios e os procedimentos utilizados para uma decisão tomada unicamente com base em tratamento automatizado, observados os segredos comercial e industrial. 


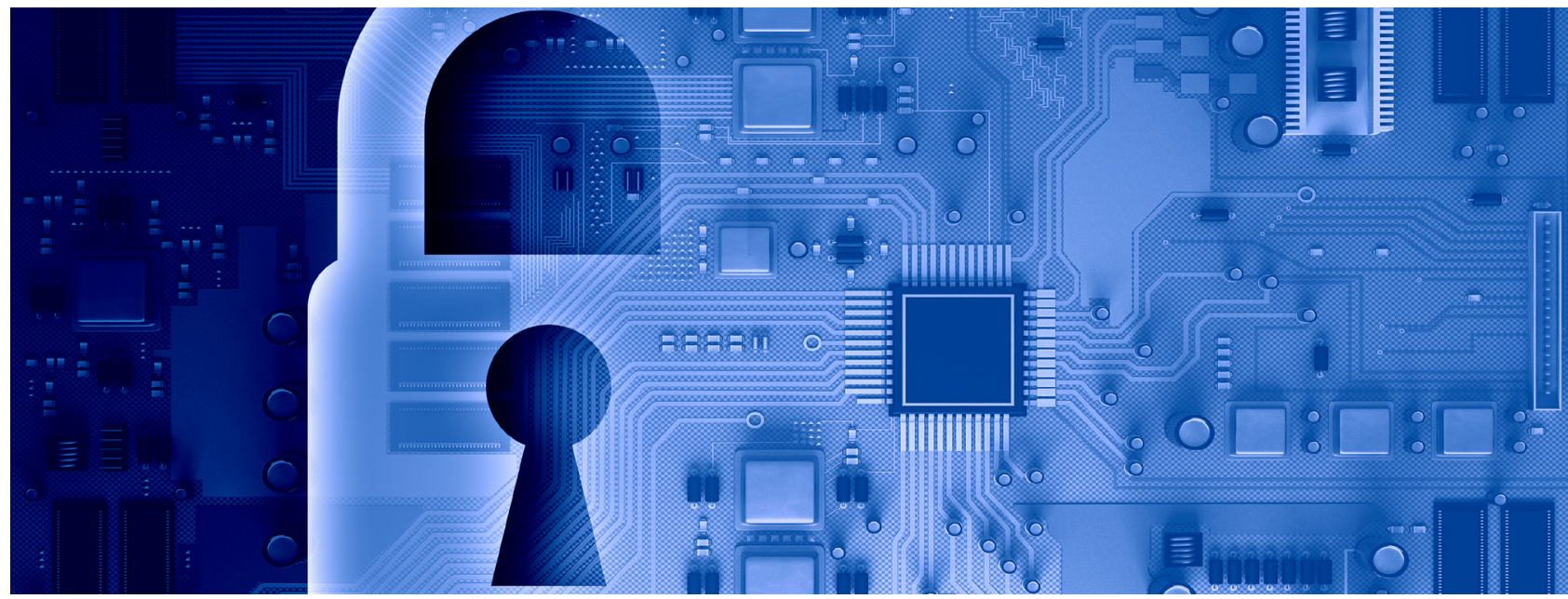

\section{COMO CUMPRI-LOS?}

Além de procurar compreender os direitos da LGPDP, os controladores estão questionando dois pontos:

- Qual é o prazo de atendimento a esses direitos;

- Qual é a forma de atender a eles?

Ainda estão bastante nublados a forma, o prazo e os critérios de atendimento a todos esses direitos, por mais que nos artigos 19 e 20 da LGPDP haja breves esclarecimentos sobre alguns. Dessa forma, o ideal é ir organizando a própria "casa" para que se possa ter conhecimento sobre todos os dados pessoais que estão presentes nas bases e nos fluxos da empresa.

Quanto ao prazo, é importante mencionar que os únicos direitos em que há indicação expressa na lei são os de acesso e o de confirmação de tratamento, sendo este último o direito de o titular ter a confirmação de que um controlador ou operador possui seus dados pessoais armazenados. A LGPDP determina o atendimento deles em até 15 dias, contados da solicitação do titular. Em relação aos demais, a lei não se atentou em estabelecer o prazo. A interpretação existente, por mais subjetiva que seja, é a de que eles deverão ser cumpridos em um prazo razoável, o que pode ser de uma semana para algumas empresas, ou de um mês para outras, dependendo da organização interna em processar os pedidos.

Para atender aos direitos da LGPDP, existem atualmente no mercado várias formas de gerenciar as requisições dos titulares. O investimento em uma ferramenta ou aplicação vai depender do volume de solicitações dos titulares e da complexidade dos tratamentos envolvidos. Caso haja baixo volume de pedidos - quando o modelo de negócio é mais focado em pessoa jurídica, por exemplo -, um canal adequado pode ser um chatbot ou e-mail, que o controlador é capaz de administrar mesmo com uma equipe pequena.

Caso o volume de requisições seja elevado e as operações de tratamento sejam complexas, o ideal é ter soluções automatizadas como um privacy dashboard (plataforma de privacidade) para gerenciar os pedidos e para o titular dos dados conseguir ter acesso imediato a alguns de seus direitos. Se a gestão for manual, será necessária uma quantidade expressiva de pessoas dedicadas a atender a todas as solicitações.

Considerando os direitos que já eram previstos nas leis setoriais brasileiras de proteção de dados e os mais recentes, gestados por conta do crescimento do tratamento automatizado de dados, é possível enxergar a fotografia atual do tema no Brasil: já havia direitos, mas não necessariamente eles eram cumpridos. Agora, com o acréscimo de novos direitos e a clara intenção de fiscalização da lei, provavelmente o cenário vai se alterar. Por esses motivos, é importante que os controladores se atentem para esse tema nesse momento, a fim de estarem em conformidade com as obrigações previstas relativas aos direitos dos titulares antes da entrada em vigor da LGPDP.

\footnotetext{
PARA SABER MAIS:

Bruno Ricardo Bioni. Proteção de Dados Pessoais: A função e os limites do consentimento, 2018 Ana Frazão. Nova LGPD: os direitos dos titulares de dados pessoais, Jota, 2018. Disponivel em: jota.info/opiniao-e-analise/colunas/constituicao-empresa-e-mercado/novaIgpd-os-direitos-dos-titulares-de-dados-pessoais-17102018

Renato Leite Monteiro. Existe um direito à explicação na Lei Geral de Proteção de Dados? Instituto Igarapé, 2018
}

MARIA CECÍLIA OLIVEIRA GOMES > Advogada especializada em Privacidade e Proteção de Dados, pesquisadora e líder de Projeto de Proteção de Dados na FGV > mariacecilia.og@gmail.com 